\title{
THE PSYCHOMOTOR THEORY OF HUMAN MIND
}

\author{
ÜNER TAN \\ Cukurova University \\ Adana, Turkey
}

This study presents a new theory to explain the neural origins of human mind. This is the psychomotor theory. The author briefly analyzed the historical development of the mind-brain theories. The close relations between psychological and motor systems were subjected to a rather detailed analysis, using psychiatric and neurological examples. The feedback circuits between mind, brain, and body were shown to occur within the mind-brain-body triad, in normal states, and psycho-neural diseases. It was stated that psychiatric signs and symptoms are coupled with motor disturbances; neurological diseases are coupled with psychological disturbances; changes in cortico-spinal motor-system activity may influence mind-brain-body triad, and vice versa. Accordingly, a psychomotor theory was created to explain the psychomotor coupling in health and disease, stating that, not the mind-brain duality or unity, but the mind-brain-body triad as a functional unit may be essential in health and disease, because mind does not end in the brain, but further controls movements, in a reciprocal manner; mental and motor events share the same neural substrate, cortical, and spinal motoneurons; mental events emerging from the motoneuronal system expressed by the human language may be closely coupled with the unity of the mind-brain-body triad. So, the psychomotor theory rejects the mind-brain duality and instead advances the unity of the psychomotor system, which will have important consequences in understanding and improving the human mind, brain, and body in health and disease.

Keywords brain, disease, health, mind, motor system, psyche

Psychomotor means "....of or relating to movement or muscular activity associated with mental processes (The American Heritage Dictionary of the

Received 14 January 2006.

Address correspondence to Prof. Dr. Üner Tan, Cukurova University, Faculty of Sciences, Department of Physics, 01330 Adana, Turkey. E-mail: unertan@cu.edu.tr 
English Language, fourth edition, 2000). This article will use "Psych" for mind, and "motor" for the motoneuronal system in brain and spinal cord. According to Hebb (1980), "broadly speaking, the mind is that which controls behavior" (p. 3). In the present work, the psychomotor system will be shown to be closely related to the mind/body (or mind/brain) problem, which has a relatively long history. The mind/body problem is concerned with determining the relationship between body and its mind. The psychomotor theory is an attempt to explain the possibilities of mind/brain unity and/or the mind/brain duality in relation to motor system in humans. To understand this theory, one has to first analyze the historical development of the mind-brain relations, at least briefly.

\section{HISTORICAL DEVELOPMENT OF THE MIND/BODY CONCEPT}

The first systematic concept of mind and body probably originates from Plato (429-347 BC). He identified mind with soul. Plato speaks of the soul as imprisoned in the body, but he does not explain what binds soul to body. Aristotle (384-322 BC) did not agree with Plato. He believed that the soul is the form of the body. His theory seems to be materialistic, but he argued that the intellect must be immaterial (a kind of dualism).

The first systematic study concerning the mind/body relationship originates from the seminal work of Rene Descartes (1596-1650), a French mathematician, philosopher, and physiologist. He is the writer of the world's first essay on physiological psychology, De Homine. Until Descartes, there was no metaphysical split between mind and body. His ideas about the mind/brain duality and the mind/brain interactionism were outlined in his book. He argued that the rational soul is distinct from body, but makes contact with it at the pineal gland; body affects mind, mind affects body; mental events can cause physical events and vice versa. This is called "interactionism" or "Cartesian dualism," that is, the dualist-interactionist theory of mind. Descartes believed that the pineal gland was the only contact side of the mind, because this gland was not bilaterally duplicated. He is famous with the principle: If I deceive, "I" must exist, "cogito ergo sum" (I think, therefore I am).

Baruch Spinoza (1632-1677) argued that there are two attributes of the same substance; reality is, therefore, a case of two perspectives on the same thing: physical matter perceived thorough senses, and mental stuff experienced by mind. Spinoza abandoned Descartes' two-substance view in favor of doubleaspect theory, which states that the mental and physical events are different aspects of the same substance. The essential substance, God, is the universal essence or nature of everything that exists. 
Psychophysical parallelism, usually traced to Gottfried Wilhelm Leibniz (1646-1716), also accepts the mind/body dualism, but avoids any causal connection between mind and body. Parallelists argue that every mental event is linked to a physical event so that when one occurs, so too does the other. The psychophysical parallelism states that mind and body exist in a harmony that has been pre-established by God.

All the aforementioned views are pointing out some distinction between mind and body. Actually, to avoid the mind/body problem, one must deny this distinction. This denial has taken different forms in history. For instance, immaterialism, best represented by George Berkeley (1685-1753), denies even the possibility of mindless material substance in his book, A Treatise Concerning the Principles of Human Knowledge (1710). According to Berkeley, there is no mind/body duality because what is thought of as body is merely a perception of mind.

Materialism argues that matter is fundamental, even in the mind/body problem. Materialism entirely denies the existence of mental events. In a less extreme form, materialism describes mental events as dependent on bodily events. This view was best explained, a century after Descartes, by Julien Offray de la Mettrie (1709-1751), who was born in Brittany and studied medicine at Paris. Because of public outcry over his materialism, he self-exiled to Holland. He then published L'homme Machine, which was publicly burned and La Mettrie was forced to seek protection from Frederick the Great at Berlin, where he continued to publish on various topics, until his death in 1751 . L'homme Machine was indeed a seminal book, which accentuated that the mental processes are identical with their physiological causes. Pierre Jean Georges Cabanis (1757-1808) argued that "to have an accurate idea of the operations from which thought result, it is necessary to consider the Brain as a special organ designed especially to produce it, as the stomach and the intestines are designed to operate the digestion and the liver to filter bile..." (Cabanis, 1805).

The nineteenth century largely engaged with the mind/body problem. Progress was made in understanding the localization of cerebral function, based on the idea that the brain serves as the organ of mind. It was generally accepted that mental events may cause radical alterations in the state of the body. At the same time, the nature of functional nervous disorders also made progress. In 1870, Shadworth Holloway Hodgson (1832-1912) published a two-volume work, The Theory of Practice, introducing the term epiphenomalism. In his book, Hodgson argued that the feelings have no causal efficacy; mental states in the central nervous system may be only epiphenomena, incapable of reflecting 
back to influence the nervous system. In support, Thomas Henry Huxley (1825-1895) presented his most influential papers on the hypothesis that animals are automata, in front of the British Association for the Advancement of Science, in 1874. He pointed out that states of consciousness are merely the effect of molecular changes in brain; animals are, therefore, conscious automata.

In 1874, another influential book was published by William Benjamin Carpenter (1813-1885), who opposed the epiphenomalism of Hodgson and Huxley. Carpenter argued that the sensational consciousness, the primary form of mental activity is excited through instrumentality. A certain physical impression is made, for example, by the formation of a luminous image upon the retina of the eye. ... Light excites nerve-force, and the transmission of this nerve-force excites the activity of that part of the Brain which is the instrument of our Visual Consciousness. Now in what way the physical change thus excited in the Sensorium is translated (so to speak) into that psychical change which we call seeing the object whose image was formed upon our Retina, we know nothing whatever; but we are equally ignorant of the way in which Light produces Chemical changes. ... And all we can say is, that there is just as close a succession of sequences-as intimate a causal relation between antecedent and consequent-in the one case, as there is in the other" (Carpenter, 1874). Interestingly enough, Carpenter has further suggested "the like Correlation may be shown to exist between mental states and the form of Nerve-force which calls forth Motion through the Muscular apparatus. . each kind of mental activity,-Sensational, Instinctive, Emotional, Ideational, and Volitional,-—may express itself in Bodily movement..." (p. 812).

Unfortunately, after 241 years from Descartes' De Homine to Carpenters Principles of "Mental Physiology," the primary objection to interactionism made little progress. In 1871, John Tyndall wrote "the passage from the physics of the brain to the corresponding facts of consciousness is unthinkable. Granted that a definite thought, and a definite molecular action in the brain occur simultaneously; we do not posses the intellectual organ, nor apparently any rudiment of the organ, which would enable us to pass, by a process of reasoning, from the one to the other" (Tyndall, 1871).

The most important brain child of Dual-aspect monism was George Henry Lewes (1817-1878), a writer, actor, biologist, philosopher, and a psychologist. His book, Physiology of Common Life, converted the young Pavlov to be a physiologist, and his five-volume book, Problems of Life and Mind (1874/1879) was a major contribution to psychology. The Physical Basis of Mind was the third volume of Problems of Life and Mind. According to his theory (neutral 
monism or dual-aspect monism), there is only one kind of "stuff" and that mind and body differ only in the arrangement of that stuff or in the perspective from which it is apprehended; when seen from the subjective point of view (e.g., thinking), the psychophysical series is mental, and when seen from the objective point of view (e.g., when one observes what happens during thinking), it is physical.

Within the nineteenth century the mind/brain problem was especially important because physiologists and psychologists focused on the nature and cerebral localization of mind. In fact, one can find ideas about functional localization throughout antiquity. For example, one can find ideas about soul globally localized to the brain in the work of Pytagoras, Hippocrates, Plato, Erisistratus, and Galen, among others. The pneumatic physiologists located the mental capacities to the fluid of the cerebral ventricles, till the book $D e$ Functionibus Systematis Nervosa was published by Jiri Prochaska in 1784, and the interest had shifted to the brain stem and cerebrum. Among the nineteenth-century achievements, the most impressive one is the localization of function to various brain regions. The most famous man of this era is Franz Josef Gall (1758-1828), who was born in Baden and studied medicine at Strasbourg and Vienna. He was impressed as a child by variations in facial and cranial appearance of his friends with unusual talents. His first lectures aroused opposition on the grounds of his presumed materialism, and in 1805, he had to leave Vienna, and after two years he arrived in Paris. Gall believed that there are correlations between character and the external craniological signs: the size and shape of the head reflect the size and shape of the underlying portions of the brain; mental abilities are innate and fixed, and the development of an innate ability is a reflection of the inherited size of its brain. In doing so, a well-developed ability can be predicted from a particularly prominent area of the cranium (functional localization of an ability in the cranium). Although Gall's correlational approach was eventually abandoned in favor of experiment, his accomplishments in the history of functional localization cannot be underestimated; he was the founder of biologically based, functional psychology.

Interestingly enough, more than 200 years later, it was found that the cognitive abilities may be predicted from the craniofacial measurements (see Dayi et al., 2002).

The first experimental demonstration of localization of function in the brain was realized by Marie-Jean-Pierre Flourens (1794-1867), using the method of complete isolation of brain part to be removed: a successive slicing through 
the cerebral hemispheres produced diffuse damage to all of the higher mental functions. Florens concluded that

higher mental functions such as perception, volition, and intelligence are spread throughout the whole brain, operating together as a single factor, the entire cerebrum functioning in a unitary fashion (unitary soul and an indivisible mind); the brain is the organ of a unitary mind, it could not, therefore, be functionally differentiated (Flourens, 1824).

The first specific demonstration of sensory-motor function originates from Alexander Bain (1818-1903), who also created a valuable survey of mind/body views (Mind and Body. The Theories of Their Relation, 1873). His important contribution was the sensory-motor associationism (associationist psychology), which was analyzed in The Senses and the Intellect (1855) and The Emotions and the Will (1859). Before Bain, the movement and action with regard to the analysis of sensation was neglected. Bain brought the new physiology of movement into relation to an associationist account of mind. He defined volition as the compound of spontaneous movements and feelings; the coordination of motor impulses into purposive movements results from the association of ideas with them.

In 1855, as Bain published The Senses and the Intellect, Herbert Spencer (1820-1903) published The Principles of Psychology. Spencer was born in Derby (England) and largely self-taught. At 17 years old, he worked as a railway engineer; in 1848, he started to work as an editor and then as a free-lance writer and reviewer. Spencer discovered a cephalograph to achieve more reliable cranial measurement. Bain had introduced movement to the sensations of associationism and arrived at the first fully balanced sensorymotor associational view; Spencer grounded psychology in evolutionary biology. For Spencer, mental phenomena are adaptations, that is, incidents of the correspondence between the organism and its environment; mental and physical life are simply species of life, mind evolves continuously from physical life, reflexes from irritations, instincts from compound reflexes, conscious life and higher mental processes from instincts:

If higher mental activities are the end product of a continuous process of development from simple irritation through reflexes, there is no justification for drawing a sharp distinction between mind and body; the brain is a physical system and the cortex is the most developed level of the brain (Spencer, 1855). 
Otherwise, the mind/brain duality continued for two centuries and supported the notion that mental processes must function according to principles entirely different from those of the brain itself.

To overcome the last obstacle to extension of the sensori-motor view to the cortex, the following period was needed. Paul Broca (1824-1880), born in France, studied medicine at the Hotel Dieu in Paris. He was an original member of the Societe d'Anthropologie and a founder of the Revue d'anthropology and the Department of Anthropology at the University of Paris.

In 1861, Broca sat in the audience as Ernest Aubertin presented a paper citing several striking cases to argue a craniological case for cerebral localization of spoken language. Aubertin was a student of Jean Baptiste Bouillaud. As early as 1825, Bouillaud provided clinical evidence to support Gall's view that the articulate language is localized in the anterior lobes of the brain. This hypothesis was kept alive for almost 40 years. Aubertin claimed that he would give up his belief in cerebral localization if even a single case of speech loss could be shown without a frontal lesion. Broca decided to take up Aubertin's challenge. His speechless patient ("Tan") had died from gangrene on Broca's surgical ward. Broca published this case, presenting a detailed account of his post-mortem examination of Tan's brain. He found a superficial lesion in the left frontal lobe. This finding was confirmed a few weeks later by another case with a similar lesion. This was the first report about the localization of the articulate language in the anterior portion of the brain. However, to be sure, the cerebral cortex should be explored experimentally in normal subjects. The technique was introduced by Gustav Theodor Fritsch (1838-1927) and Eduard Hitzig (1838-1907).

Fritsch and Hitzig, in 1870, published a classic paper, providing evidence of cortical localization of function. Namely, using galvanic stimulation of the dog brain, they provided the first evidence that areas of the cerebral cortex are involved in movements of the contralateral extremities. These results established electrophysiology for the experimental exploration of cortical localization of function, which demonstrated the participation of brain in motor functions. At approximately the same time in England, John Hughlings Jackson (1835-1911) started brain from a different direction. He was a physician at the National Hospital for the Paralyzed and Epileptics, Queen Square. His ideas can be summed up as follows:

All complex mental phenomena are made up of these simple elements-from the simplest reflex to the most sublime thoughts; all functions and faculties can be explained in these terms .... It is asserted by some that the cerebrum is the organ of mind, and that it is not a motor organ. Some think 
the cerebrum is to be linked to an instrumentalist, and the motor centers to the instrument - one part is for ideas, and the other for movements. It may, then, be asked, How can discharge of part of a mental organ produce motor symptoms only? ... But of what 'substance' can the organ of mind be composed, unless of processes representing movements and impressions...? Are we to believe that the hemisphere is built on a plan fundamentally different from that of the motor tract? ... Surely the conclusion is irresistible, that mental symptoms ... must all be due to lack, or to disorderly development, of sensory-motor processes (Jackson, 1873).

With Jackson, the theoretical analysis of cerebral localization reached its full development in the nineteenth century. These results were fully confirmed by his friend and colleague, David Ferrier (1843-1928), who using controlled ablations and faradic stimulation of the brain, succeeded in mapping sensory and motor areas across a wide range of species. This was the dominant paradigm for explanation in both physiology and psychology.

The concept of subconsciousness emerged in the nineteenth century. This was an epoch of trance and trauma (functional nervous disorders). The most prominent scientist of this area was Franz Anton Mesmer (1734-1815), born in a German town, and studied medicine at the University of Vienna with a dissertation on the influence of the planets on human disease. Mesmer had a patient, Madame Oesterlin (27 years), who suffered from recurring physical ailments. On 28 July 1774, he asked his patient to swallow a solution containing iron and affixed magnets to her stomach and legs. Her symptoms began to disappear, and she completely recovered with continued treatment. Unfortunately, the results were not confirmed by others and Mesmer had to leave for Paris, where he further developed his "magnetic cure." However, he also had to leave Paris after several spectacular therapeutic failures, and died near the place of his birth.

In the history of Western philosophy, one of the most influential philosophers is Immanuel Kant (1724-1804), who was born, lived, and died at Koenigsberg, East Prussia. During his life he did not travel more than forty miles from his birth place. His most original contribution is his "Copernican Revolution": the representation that makes the object possible rather than the object that makes the representation possible; the human mind is an active originator of experience rather than just a passive recipient of perception; perceptual input must be processed (recognized), otherwise it would be a noise or nothing. Kant argued that mind plays an active role in constituting the features of experience, limiting the mind's access to the empirical realm of space and time; "thoughts without content are empty, intuitions without 
concepts are blind" (Kant, 1871). In the philosophical classic, Critique of Pure Reason, he asserted that human perceptual apparatus is capable of ordering sense-impressions into intelligible unities, leading to the conclusion through "pure reason" that the intelligible unities, such as God, freedom, and immortability, do exist. Kant did not describe himself as "dualist," in contrast to Plato who believed that there is a world beyond the material world, soul or mind; he insisted that none of reality exists; reality and all that is in it, including human beings are part of this outer world, all part of a dream world. Kant argued that the universe did not consist of matter but of forces.

Kant proposed that the objective reality is the essential structure of the knowing mind. Only objects of experience can be known, whereas things lying beyond experience are unknowable. The unknowable "things-in-themselves" can be neither confirmed nor denied, nor can be scientifically demonstrated. Accordingly, he showed in the Critique of Pure Reason that the great metaphysical problems, such as God, freedom, and immortability, cannot be solved by scientific thought.

During this time period, another philosopher of mind, Johann Friedrich Herbart (1776-1841), was concerned with the new scientific psychology, making a critical distinction between ideas above and below the threshold of consciousness. He was a transitional figure between Kant and Fechner; he was not able to link his philosophy of mind to the physiology of the brain. Evangelista Purkyne (1787-1869) and Ernst Heinrich Weber (1795-1878) made fundamental contributions to the experimental phenomenology of sensation, and Johannes Mueller (1801-1858) elaborated the doctrine of specific nerve energies, suggesting the nervous system as intermediary between mind and the world. Weber described the just noticeable difference, which refers to the smallest perceptible difference between two sensations. He played an important role in the emerging science of psychology. Weber provided evidence for the relationship between variations in physical and mental events. According to Mueller, the mind is directly aware of the states of the nervous system. That is, the nervous system plays a role as an intermediary between the world and the mind and thus imposes its own nature on mental processes. After that, the quantitative measurement of the mind/body relationship emerged in Fechner's psychophysics.

The experimental psychology formally started with Gustav Theodor Fechner (1801-1887). Before that, there was only psychological physiology and philosophical psychology. Fechner was born in Prussia. At 16, he began to study medicine at the University of Leibzig; after earning his M.D. he began to study physics and mathematics. He suffered a nervous collapse, 
in 1840 , as his article on subjective afterimages appeared. He had a painful injury to his eyes while gazing at the sun during his research. This resulted in temporary blindness and prostration. He resigned his position and his interests changed to metaphysics. In 1848 , he returned to the University as a professor of philosophy; he wrote a book, Nanna, Ueber das Seelenleben der Pflanzen, which contained his first philosophical treatment of the mind/body relation (monistic, dual-aspect, pan-psychical mind/body view). Fechner wanted to demonstrate the unity of mind and body empirically by relating increase in bodily energy to an increase in mental intensity.

Between 1851 and 1860, Fechner worked on the measuring sensation indirectly and found a just noticeable difference between the two sensations. Working out this subject, he concluded his book, Elemente der Psychophysik. His aim was to establish an exact science of the functional relationship between physical and mental phenomena, and formulated his famous principle that the intensity of sensation increases as the $\log$ of the stimulus $(S=k \log R)$. In doing so, he believed that he had arrived at a fundamental philosophical truth: mind and matter are simply different ways of conceiving of one and the same reality. Mental events were shown not only as able to be measured, but also brought into relation to physical phenomena; psychophysics became one of the methods of the newly emerging scientific psychology. Wilhelm Wundt (1832-1920), physiologist, also rejected a metaphysical foundation of psychology. Wundt argued that the limitations of the direct study of consciousness can be transcended using genetic, comparative, statistical, historical, and particularly experimental methods. Only in this way would it would be possible to understand the conscious phenomena as "complex products of the unconscious mind" (Wundt, 1862).

Hermann Ludwig Ferdinand von Helmholtz (1821-1894) born in Postdam (Germany), graduated in medicine at 21 years of age and was interested in a physiological basis of animal heat. He calculated the conduction velocity of a nervous impulse, by stimulating nerves at various distances from a muscle and measuring the time it took for muscle contraction, and introduced the technique for measuring the reaction time into physiology. Between 1865 and 1868, another great physiologist, Franciscus Cornelis Donders (1818-1889) developed and assimilated the reaction time to psychology. Donders separated the time taken to respond to a stimulus under conditions of choice and non-choice. In doing so, Donders calculated the time interval taken by the decision process. His discoveries with respect to mental reaction times exerted a major impact on his contemporaries and reaction time was installed, along with psychophysics, as a method of choice in early experimental psychology. 
The most influential neurophysiologist and philosopher of the nineteenth century was Sir Charles Sherrington (1857-1952), who completed his medicine study at the Royal College of Surgeons. First he worked on the effects of excisions of parts of the cortex of dog brains. In 1885, he went to Spain to study an outbreak of cholera; in 1886 he visited Venice to investigate this disease, then he took the material to Virchow in Berlin for further examination. While in Spain, he was influenced by the Spanish Neurologist Ramon y Cajal, and took up the study of the spinal cord, and began to study the spinal reflexes. After the passing of the man of genius on 4 March 1952, Sherrington left more than 350 works on the foundations of knowledge of the functioning of the brain and spinal cord. His work Integrative Action of the Nervous System (1906) is still a source of inspiration to physiologists all over the world. Sherrington did not retire from the Chair of Physiology at Oxford until 1935 at the age of seventy-eight. After making experiments with cats, dogs, and monkeys, he became a philosopher and was interested in the mind/body relationship. He had a dualist position in the mind/body controversy. Five days before his death, he said to Sir John Eccles, one of his prominent pupils: "For me now, the only reality is the human soul" (Eccles, 1975).

According to Sherrington,

.... mind is attached to a voluntary motor act performed with skill. "What the mind is concerned with is not the act but the aim. It is more aware of the finger-part than the rest Because the fingers' part stands nearest to the aim. ... Clearly we must not suppose 'life' and 'mind' are one and the same. The finite life is a phenomenon accessible to sense; the finite mind is not. (Sherrington, 1953)

What is most important for the subject of the present work is that "mind, recognizable mind, seems to have arisen in connection with the motor act. Where motor integration progressed and where motor behavior progressively evolved, mind progressively evolved."

One of Sherringtons most notable students was the Canadian neurosurgeon Wilder Penfield (1891-1976). He established the Montreal Neurological Institute in 1934. In the 1950s, Penfield was trying to treat epileptic patients, removing or destroying the brain tissue responsible for seizures. He made a dramatic discovery at the same time: stimulating only the temporal lobe elicited meaningful, integrated responses such as memory for sounds, movements, and color. These memories were distinct from usual memories, which were unremembered under ordinary circumstances. If he stimulated the same area 
again, the same memory appeared again. He believed that he found a physical bases of memory (engram). He also interested in "mind"; until his death in 1976 questioned the scientific basis of mind, whether there is a scientific basis for the existence of the human soul, and stated:

Throughout my own scientific career, I, like the other scientists, have struggled to prove that the brain accounts for the mind. But now, perhaps, the time has come when we may profitably consider the evidence as it stands, and ask question: Do brain mechanisms account for the mind?. Can the mind be explained by what is now known about the brain? If not, which is the more reasonable of the two possible hypothesis, that man's being is based on one element, or on two? (Penfield, 1975)

First, Penfield offered an entirely mechanistic interpretation of the brain functions. But subsequently, he was convinced that this mechanistic and monistic view cannot explain the facts: "something else finds its dwelling place between the sensory complex and the motor mechanisms" (Penfield, 1975).

As Penfield worked during his training with Sir Charles Sherrington and for a short period under Santiago Ramon-y-Cajal in Spain he believed that mind will be entirely explained in terms of physics, chemistry, and electricity. But later, he thought that this mechanistic and monistic view did not adequately account for the facts. He had a surprising and remarkable experience as a form of double consciousness in one of his subjects during temporal lobe stimulation. The patient was aware of his immediate surroundings, and at the same time he re-enacted scenes from the past with vivid sounds, and so on. Another patient from South Africa was also aware of his environment in the operating room, but he was, at the same time, laughing with his cousins on a farm in South Africa. According to Penfield, the mind of the patient was independent as was the mind of the surgeon listening to and understanding him: "thus, my argument favors independence of mind-action " (Penfield, 1975). Penfield concluded that the stimulus was responsible for a kind of TV program the subject watched objectively, while the subject's mind was directing to record the events in the room around him. Just as one can objectively watch a TV program in the company of others whose presence one is fully conscious of, so here were two different types of consciousness. He emphasized that it is the mind that must first program the computer brain, which has no ability to make totally new decisions for which it is programmed. Stimulation of the same point in the temporal cortex induced the same scenes. This was repeatable; in one subject this occurred sixty-two successive times. However, in another subject, the 
stimulation of the same area caused four apparently unrelated responses. First he heard "footsteps," secondly "a company of people in the room," thirdly "like being in a gymnasium," and finally "a lady talking to a child at the seashore." The experiences were not as a kind of hallucination but as a real life. In the end, Penfield concluded that "it is easier to rationalize man's being on the basis of two elements than on the basis of one" (Penfield, 1975).

In 1961 Penfield demonstrated the reality of active mind or free will. He stimulated an area in the cerebral cortex with a single electrode using an electric shock at $60 \mathrm{~Hz}$ frequency and 2 volt intensity. When the neurosurgeon applied this stimulation to the motor area, the opposite hand moved, as expected. Surgeon asked the patient, why he moved his hand. The response was: I did not do it, you made me do it. "It may be said that the patient thinks of himself as having an existence separate from his body" (pp. 203-204). Penfield goes on: "Once when I warned a patient of my intention to stimulate the motor area of the cortex, and challenged him to keep his hand from moving when the electrode was applied, he seized it with the other hand and struggled to hold it still. Thus one hand, under the control of the right hemisphere driven by an electrode, and the other hand, which he controlled through the left hemisphere, was caused to struggle against each other. Behind the brain action of one hemisphere was the patient"s mind. Behind the action of the other hemisphere was the electrode" (pp. 203-204).

Sherrington's mind/body dualism was followed not only by Penfield in Canada, but also by another pupil, Sir John Eccles (1903-1997). Eccles is recognized for his remarkable and outstanding impact on the neurosciences for more than six decades. Moreover, his essays on the mind/brain interaction generated considerable interest and debate. He studied science and mathematics at Melbourne High School, before entering the University, shared the State geometry prize and gained a Senior Scholarship to the University. He was deeply interested in mathematics, but chose medicine to study. He was interested in Darwin's Origin of Species in the first-year zoology course, and in philosophy dealing with the mind/body problem. Because of the unsatisfactory explanation of the interaction between brain and mind, he decided to be a neuroscientist. At Oxford, he spent two years studying for the Final Honours School in Physiology and Biochemistry; he read the neurophysiological, biochemical, philosophical, and theological books. He worked with Ragnar Granit on the crossed extensor reflexes. In 1935, Sherrington retired and was replaced by J. Mellanby. Eccles was disappointed and was also concerned about the increasing political uncertainty in Europe. He resigned his Oxford appointments and went to Sydney with his family in 1937. Eccles resigned in 
1943, however, because of a debate between him and the hospital board, and accepted the Chair of Physiology in Otago (New Zealand), where he recorded ventral root responses to dorsal root stimulation, dorsal root potentials upon dorsal-root stimulations, which were described by Barron and Matthews in 1938. The results were consistent with an electrical hypothesis of synaptic and neuromuscular transmission, as published in Nature (1945).

Eccles encountered K. R. Popper in New Zealand. He was deeply impressed by Popper's philosophy: "the scientific hypotheses should be clearly formulated and testable by experiment; the strength of a hypothesis depends upon the failure of rigorous investigation to falsify it rather than on evidence which apparently supports it" (Popper, 1935). He had a long-lasting debate with Henry Dale about the origins of the synaptic transmission. Eccles insisted of electrical transmission in contrast to Dale who insisted of chemical transmission. Eccles stated his hypothesis of electrical excitatory transmission at central and ganglionic synapses, and the neuromuscular junction, proposing a number of physiological and pharmacological experiments. Accordingly, he tested this hypothesis in 1946 with C. McC. Brooks by recording the monosynaptic excitation from the spinal motoneurones. The results were interpreted as consistent with his electrical hypothesis, and were published in Nature.

In 1949, Eccles restated his electrical hypothesis using synaptic excitation and inhibition in the spinal cord. However, his studies with Kuffler and others convinced him in 1948 that transmission at the neuromuscular junction was a chemical process mediated by Ach. In 1951, he considered his hypothesis to have been falsified, and accepted that spinal excitation and inhibition were both chemical in nature. After this year, he accepted an invitation to Canberra.

He was involved in the mind/brain problem at the same time. His dualistic view, a neurophysiological hypothesis of will, first published in Nature, created intense discussion. His lectures were published in 1953 as The Neurophysiological Basis of Mind: The Principles of Neurophysiology.

After 1952 onward for nearly 13 years, Eccles was most productive in Canberra: 74 investigators from 20 different countries worked with him during this time. He later wrote: "Without doubt it was the high point of my research career... my 14 golden years, scientifically speaking” (Eccles, 1977). He had six large research laboratories with co-workers interested in neuropharmacology and neurochemistry. In 1958, he recorded the dorsal root potentials intracellularly from intraspinal afferent fibers, and prolonged EPSPs from dorsal horn interneurones involved in DRPs. The period of 1961-1965 was full of publications (29 full papers, 13 review articles, and one book) dealing 
with presynaptic inhibition. In the ventrobasal complex of the thalamus he made two interesting observations: a recurrent inhibition and large post-inhibitory "rebound" depolarizing responses with superimposed bursts of action potentials (rhythmic thalamic activity). Eccles" last period of experimental neuroscience, concerned with the cerebellum, began in Canberra in 1963 and continued in the United States until his retirement in 1975. The results were published in a series of articles in Nature and in a book, The Cerebellum as a Neuronal Machine. An important factor in Eccles' decision to leave Australia was his feeling of intellectual isolation, especially concerning his philosophical interest in mind/body interaction. In 1975, Eccles voluntarily retired and moved to Contra in Switzerland, where he dedicated himself to work on the mind/brain problem. How the Self Controls its Brain was published in 1994. Throughout his mental life, he had been a dualist, searching for mechanisms by which mind and brain interact. However, only $18 \%$ of his 568 publications dealt with this subject. In The Self and Its Brain, he summarized his views:

It is a very strong dualism and raises the most severe scientific problems in relationship between the world of matter-energy, and the world of states of consciousness that is referred to as the self-conscious mind. Briefly, the hypothesis states that the self-conscious mind is an independent entity that actively engages in the reading out from a multitude of active centers in the modules of the liaison areas of the dominant cerebral hemisphere. (Eccles, 1977)

He also suggested that the mind/brain liaison functions in both directions, from the brain to the mind in perception and from mind to brain in willed action: "The self-conscious mind interacts with the brain on aggregations of cortical pyramidal cell dendrites" (p. 371).

Eccles actively participated in the experiments from 1927 to 1975 . He had a strong motivation and stamina for an outstanding scientific career. He also owed much of his success to his productive research teams. He was a profilic writer with 568 items, including 19 books. His experiments usually began early in the morning each week, often lasting 16-20 hours, occasionally extending into the following day. He always had the best equipment in his laboratories including the first-class electronic and mechanical workshop personnel and facilities. As Eccles decided to move to Chicago in 1966, his wife preferred to stay in Australia, and their marriage was dissolved in 1968. In the same year Eccles married Helena, a neurophysiologist who collaborated with him from 1966 until he completed experimentation in 1975 , after which they moved to 
Switzerland, where Eccles continued to work on the mind/brain problem. Until well beyond his 90th year, he had a long series of books, articles, reviews, comments, book reviews, and obituaries, which all were hand-written. He was always assisted in these activities by his wife Helena. He had bad health, however, from 1994 on, and he died in 1997 in the Hospital La Carita in Locarno.

The dualist-interactionist view of the mind/brain problem underwent a considerable change because of Roger W. Sperry (1913-1994), who offered the most contemporary hypothesis on the subject. He was born in Hartford (USA), stayed in Oberlin for an MA in Psychology (1937), and received his Ph.D. (1941), in Zoology. He argued that the basic structure of the mammalian central nervous system is hard wired, and unmodifiable by training. He was uncomfortable with the idea that electrical fields or waves were critical for neocortical processing. He demonstrated in monkeys that motor coordination remained unaffected after multiple transactions of sensorimotor cortex. $\mathrm{He}$ is famous for the "split-brain" experiments. In commisurotomized animals, restriction of sensory input on one cerebral hemisphere was shown to limit the learning activities to that hemisphere; the other brain half was capable of learning but remained naïve to those tasks until trained; the learning curves for each hemisphere was the same; it was as if two separate brains were housed within a single cranium. Sperry carried out much work during 1950s and 1960s on the split-brain preparation. Then Sperry studied the effects of commissurotomy on perception. The left brain was found to be involved in analytical, sequential, and linguistic processes, and the right brain in holistic, parallel, and spatial abilities. Moreover, the combined effect of bi-hemispheric activity was more than the simple additive effects of the two separate hemispheres. Sperry then began to explore the emergence of consciousness from the unified brain:

I have never been satisfied with the materialistic or behaviorist thesis that a complete explanation of brain function is possible in purely objective terms with no reference whatever to subjective experience, i.e., that in scientific analysis we can confidently and advantageously disregard the subjective properties of the brain process.... The mental forces are inseparably tied to the cerebral structure and its functional organization. ... In contrast to mind-brain identity theory, in the present theory the conventional differences between mind and brain are accepted and emphasized. ... The brain process consists of a multilevel hierarchic compound of entities and events from subatomic up through cerebral circuit and cognitive levels, 
is composed mostly of nonconscious elements that are common both to conscious and nonconscious brain processes.... The brain process and the conscious processes are inseparable but different. The difference between minds and brain is the kind which exists between an emergent property and its infrastructure. ... Subjective experience in this interpretation is conceived to be an emergent dynamic property of cerebral excitation, inseparable from the material brain process, but different from and more than, the collected sum of the physicochemical components.... The conscious experience is a property of, and cannot exists apart from the cerebral substrate. (Sperry, 1980)

According to Sperry, emergence occurs when, for instance, subparticles, atoms, and molecules create a new entity with new properties formerly nonexistent in the universe. Sperry did not see this as dualism, which describes the mind as a separate entity outside the brain. Consciousness emerges from the creativity of cerebral networks as an independent entity, which continually feeds back to the brain, causing new dynamic processes in the brain, feedback (downward causation) with newly emergent states, and so forth.

Materialism (physicalism) refers to the idea that humans are completely physical beings; there is no mind separate from brain; the concepts of a soul or mind are only mythical; every event including mental phenomena may be explained by matter and motion. Materialism is the simplest explanation of reality: no psychic or spiritual truths exist independent from the physical world. Philosophical materialism claims that there is only one substance in the universe: physical, empirical or material; everything is matter and energy; consciousness is an emergent property of the physical brain. The existence of a supernatural God is denied, but God is identified with the material universe, as in Pantheism. Materialism originated in ancient Greek philosophy, in China, and India, during the sixth century BC. Analytical materialism deals with the so-called mind/brain problem: whether or not human consciousness can be explained by scientific laws. In the 1960s and 1970s, it was argued that the brain and mind are the same material things. Reductionist materialism claims that the mind is identical to the brain in all respects; mental states are identical to brain states; mental processes are reducible to physical facts. Behaviorism claims that there is no mind; vague talk about feelings, thoughts, desires, and so on should be eliminated from the vocabulary and replaced with scientific terms referring only to brain states. 


\section{MIND-BRAIN-BODY TRIAD IN HEALTH}

From the beginnings of ancient history there is dance as an expression of God. Through movement and sound, this created a connection to spirit. Spiritual dancing is a cross-cultural phenomenon. Dance was used to promote spiritual and physical health, and vitality. An ancient dance type, trance dance, was a healing vehicle through which people could communicate with their spirit. Today, there are dance/movement therapies, which are the psychotherapeutic processes improving the emotional states, cognition, and the social and physical integration of the individual.

Dance is the esthetic expression of mind in bodily movement. Dance originates in a discrete bodily-kinesthetic "intelligence" (Gardner, 1993); skilled movements is a form of thinking (Bartlett, 1958; Fischer \& Bidell, 1998); movement is predominant in all forms of human intellectual activity (Laban, 1975; Laban \& Lawrence, 1974). Rhythmic movements in dance inject itself into all cognitive actions including our mind and self-conscious brain. Indeed, "self-generated movement is the foundation of thought and willed action, the underlying mechanism by which the physical and psychological coordinates of the self come into being" (Wilson, 1998, p. 291).

Yoga creates a mind/body connection by using awareness of the breath and concentration of the mind. In the mind/body approach, exercises are taken from yoga, tai chi, aikido, and from dance movement therapy, to enhance awareness of breathing, increase ability to breathe, experience the interplay among the physical, mental, emotional, and spiritual aspects of well-being, feeling powerful, and feeling graceful (Eckstein \& Keeling, 1991). Considering breath and mental activity, it was interestingly found that the nonverbal IQ (Cattell's Culture Fair Intelligence Test) increased with tidal volume of the lungs in human subjects (Tan et al., 2003). It was also reported that aerobic dance is beneficial in the therapy of anxiety (Kern \& Baker, 1997). Moreover, exercise has been reported to have tranquilizing and antidepressant effects on participants (Berger, 1984).

In addition to voluntary active movement as occurred in dance, the gentle rhythmical movements performed with hands on a subject can induce positive and long-term changes (Blackburn, 2003): The clients, although passive, would become aware of very pleasurable sensations in their bodies, and learnt then to replicate these movements for themselves. This method was proven to be effective not only in healthy subjects, but also in patients with cerebral palsy, post-polio-related paralysis, muscular dystrophy, and Parkinson's disease. 
Dance was recognized as a therapeutic agent first after the 1930s (dance therapy). It was used in the treatment of anxiety disorders (Leste \& Rust, 1990), Parkinson's disease (Westbrook \& McKibben, 1989), addictions (Murray-Lane, 1995; Rose, 1995), multiple personality disorder (Baum, 1995), and learning difficulties (MacDonald, 1992). Cohen and Walco (1999) reported that even in cancer cases dance therapy may have beneficial effects on the cognitive, emotional, and social activities.

The reported studies suggest that movement may occupy a central position in cognitive actions. There is an information-processing system relating to movement and cognitive actions, such as planning, reasoning, and emotion (Leiner et al., 1989). The cerebellum, known to be involved only in voluntary and involuntary motor control, also plays a major role in thought itself (Leiner et al., 1986); the resulting information-processing system may be essential for the manipulation of kinesthetic mind. In accord, it was posited that thinking is an advanced form of skilled behavior that evolved from earlier forms of flexible adaptation to the environment (see Barlett, 1958). Interestingly enough, it was reported that mental practice alone may improve physical skills (Hinshaw, 1992; Ogles et al., 1994).

Disorders in the fronto-thalamo-cerebellar circuit may cause "cognitive dysmetria" or problems in information processing, which may play a role in the origins of schizophrenia and other mental illnesses (see Andreasen et al., 1998). The spinal cord, as a part of the central nervous system, should also involved in this network. Namely, in schizophrenia patients, the spinal motor asymmetry disappeared after chlorpromazine treatment (Tan \& Gurgen, 1986). The "cerebellar cognitive affective syndrome" is associated with disturbances in language (e.g., agrammatism), personality (e.g., blunted affect), spatial cognition (e.g., deficits in visuospatial memory), and executive functions (e.g., difficulties in planning); cerebellar lesions are linked to disturbed affect, and problems in cognitive processing, especially in posterior lobe lesions (see Seitz, 2000). The parallel evolution of the frontal lobe regions (speech?) and hands in hominids suggests motor activity as the basis of human intelligence (Seitz, 2000).

There are more examples indicating psychomotor coupling. For instance, there are cognitive (e.g., dementia and depression) as well as motor deficits in defects of basal ganglia, substantia nigra, locus ceruleus, and raphe nuclei of the brain stem. These symptoms are characteristic for Parkinson's disease exhibiting an increase in inhibitory signals leading to a decrease in cortical excitation and movement (see DeLong, 1990), and for Huntington's disease exhibiting a reduction in inhibitory action leading to an increase in 
cortical excitation and movement (Middleton \& Strick, 1994). Cerebellum is now known to play an important role, along with basal ganglia, in planning, regulation, and attention (Akshoomoff \& Courchesne, 1994); the developmental deficits in cerebellum may lead to poor social and cognitive development even in the absence of an hippocampal damage.

The posterior parietal cortex, another motor region, is responsible for creating a frame of reference (i.e., spatial, visual, vestibular) for movement (Willingham, 1998). Ito (1993) suggested on page 449 that "there is no inherent distinction between thought and movement at the level of the brain; both can be controlled by identical neural systems." "Therefore concepts and ideas can be manipulated just as are body parts in motion" (Seitz, p. 24, 2000).

Contemporary researchers have recently proposed that there are two distinct cognitive systems (Dual-process theory; Evans, 2003): System 1 describes a form of universal cognition shared between humans and animals (instinctive behaviors controlling specific behaviors); System 2 evolved much more recently than System 1 (volitional) is thought to be uniquely human, and permits abstract thinking not present in System 1. Briefly, the dual-process theories of thinking and reasoning propose the presence of two minds in one brain.

The spinal motor system is also involved in cognitive actions. Paillard (1955) found that the number of motoneurones increased during mental arithmetical calculations: the T-reflex amplitude enhanced, but there was no change in the H-reflex (Hoffmann reflex, a counterpart of the monosynaptic stretch reflex) amplitude. Considering handedness, Davis (1937) reported that arithmetical calculations produced EMG gradients in the right forearm extensor muscles in right-handers. As well known, the paired Hoffmann reflex produced by double shock stimulation of the tibial nerve provides a measure of motoneuronal excitability under a variety of experimental and clinical conditions. It is also a useful tool in examining the neurophysiologic basis of alterations in reflex response in different states of awareness. Using this technique, Wallace et al. (1984) found that the facilitation period of the paired $\mathrm{H}$-reflex recovery curve may be a useful indicator for the academic achievement. Accordingly, Tan (1991) reported that there is an inverse correlation between the latency of the Hoffman reflex recorded from the thenar mucles of the right and left hands and nonverbal IQ: high IQ was associated with higher motoneuronal excitability, and vice versa. Concerning the more peripheral nervous system, Tan (1996) found that the sensory and motor median-nerve conduction velocity was positively linearly correlated with IQ in men. 
With regard to the mind/body relation, Dayi et al. (2002) reported that Cattell IQ (nonverbal) linearly increased with the right- minus left-face width in left-handers, and negatively correlated in right-handed men and women; verbal ability inversely related to right- minus left-face width in right- and left-handed men, but directly correlated in right-handed women; the mental rotation ability positively and linearly correlated with the right- minus left-face width in left-handers and right-handed women. The authors concluded that "the structural functional coupling revealed in the present work may have its origins in parallel development of the craniofacial skeleton and brain under the influence of homeobox genes" (p. 383).

IQ is closely related to spinal-motor activity, assessed by Hoffmann reflex in humans (Tan, 1989a), and to hand skill in right- and left-handed subjects (Tan, 1989b, c; Tan 1990).

\section{MIND-BRAIN-BODY TRIAD IN DISEASE Parkinson's Disease (PD)}

$\mathrm{PD}$ is a disorder of motor system exhibiting a triad of akinesia, rigidity, and tremor. It is, however, accompanied by non-motor manifestations, such as neuropsychiatric, perceptual, and cognitive deficits. James Parkinson described melancholia in his original report concerning the disorder referred to his name. Depression is one of the major non-motor symptoms occurring in $4 \%$ to $75 \%$ of patients with PD (Allain et al., 2000; Ranoux, 2000). The surveys, however, suffer from a number of methodological flaws (see McDonald et al., 2003). Parkinson's disease is characterized by a series of motor system disturbances, such as tremor, rigidity, slowness of movement, and abnormalities of posture. In addition, there are nonmotor symptoms like mood changes, and cognitive deterioration. In many countries, including the United States, approximately half of PD patients had depressive symptoms (see McDonald et al., 2003). "The diagnosis of depression in PD is particularly difficult because the symptoms of PD overlap with the symptoms of depression" (McDonald et al. p. 363, 2003). Parkinson patients often have psychological disturbances, such a psychomotor slowing, concentration difficulty, depressed mood, and diminished sexual activity.

Their facial appearance typically resembles that of melancholics. Various depression scales were used to asses depression in PD, but there is no scale specific to comorbid depression in PD; the accurate diagnosis of depression in PD is complicated by various factors; the DSM diagnostic criteria for major depression do not adequately describe the PD patients with subsyndromal 
depression (see McDonald et al., 2003). So, the prevalence of depression in PD remains controversial.

\section{Motor Neuron Disease (MND)}

A motoneuronal disease with mental disorders is the amyotrophic lateral sclerosis (ALS), which is simply called as Motor Neuron Disease, actually comprising a series of motor neuron disorders, such as progressive bulbar palsy, amyotrophic lateral sclerosis, spinal muscular atrophies, Kugelberg-Welander syndrome, Duchenne's paralysis, Werdnig-Hoffmann disease, Juvenile spinal muscular atrophy, and infantile spinal muscular atrophy. MNDs may affect the upper (from brain to medulla or spinal cord) and lower motor neurons (from spinal cord to skeletal muscles). As a result of MND/ALS, the skeletal muscles weaken and lose their ability to move; many muscle groups may be affected, including those that control swallowing and breathing as well as muscles in the arms, legs, back, and neck. Generally, the terms MND and ALS are used interchangeably. As early as in 1932, a combination of MND with mental symptoms was reported, and psychic disturbances accompanying ALS were reported in the nineteenth century (see Bak \& Hodges, 2001). The most common psychiatric symptoms observed in MND are emotional changes including depression, manic-depressive illness, emotional irritability, at times culminating in violent and uncontrollable outbursts of rage. Emotional symptoms are often observed with other changes in personality and behavior, ranging from suspiciousness to outright delusions and hallucinations, including psychotic symptoms such as paranoid and catatonic schizophrenia (Bak \& Hodges, 2001). Because the MND frequently occurred with cognitive impairment, it was considered as a multiple system disorder. Barson et al. (2000) found that $22 \%$ of patients with MND were diagnosed with dementia. Most studies on mental functions in MND concentrated on the dramatic decline seen in MND/dementia complex. The other cognitive functions not related to dementia are also being studied nowadays in MND patients. Interestingly, Abrahams et al. (1997) suggested a link between the presence of the pseudobulbar palsy and the severity of cognitive deficits; the motor component of dementia in MND mostly involves the bulbar and proximal upper limbs, and dementia shows similarities with the frontal variant of frontal-lobe dementia, which also shows motor abnormalities. The cognitive symptoms in MND/dementia almost always precede the motor symptoms; the opposite is quite rare. Cooper et al. (1995) found ubiquitin-positive tau-negative intraneuronal inclusions in hippocampus and spinal cord, one of the features of MND/dementia complex. 
Ito et al. (2001) reported a motor neuron disease with presenile dementia as well as bilateral degeneration of the pyramidal tract on cranial MRI. Portet et al. (2001) found that $48 \%$ of their patients with MND/ALS were cognitively impaired, exhibiting memory impairment, alteration in judgment and reasoning, and so on. The authors concluded that there is a continuum between MND/ALS and fronto-temporal lobe dementia. The continuum hypothesis was also supported by Wilson et al. (2001), who reported a diffuse intraneuronal Ub inclusions in cortical, hippocampal, and subcortical regions in MND-patients with cognitive impairment.

Interestingly, the spinal cords of the patients with parkinsonism/dementia complex with or without ALS, or Alzheimer disease contained neurofibrillary tangles, also found in cortical gray matter of patients exhibiting Alzheimer disease and ALS/dementia complex (Schmidt et al., 2001). Furthermore, the fronto-temporal dementia exhibiting ubiquitinated inclusions in hippocampus and fronto-temporal cortex may involve lateral corticospinal tracts and spinal motor neurons typical of MND. This is consistent with the hypothesis that the pathological changes of pure MND and MND with dementia form a spectrum, and show that pathological involvement of the motor system may occur in MND-dementia without clinical evidence of MND (Holton et al., 2002).

MND with dementia can also include degeneration of the striatonigral and pallidoluysian systems, in addition to neuronal loss in the upper and lower motoneuronal system and fronto-temporal cortex (Sudo et al., 2002).

To understand the relation of MND to cognitive disturbances, more specific and more sensitive neuropsychological test batteries must be used to detect and study the entire disruption of cognitive processes in dementia related to MNDs (Moretti et al., 2001). In fact, there are accumulations of argyrophilic tau immunoreactive inclusions in neurons of spinal cord, brain stem, and neocortex in tau $\mathrm{Tg}$ mice, similar to human taupathies; because the inclusions were most abundant in the spinal motor neurons, the taupathy in these mice resembles ALS/PDC (amyotrophic lateral sclerosis/parkinsonism dementia) wherein tangles are abundant in spinal cord (see Trojanowski et al., 2002).

Both Alzheimer's and Parkinson's diseases could share the same neural substrates, that is, morphologically homogenous groups of subcortical neurons extending from the midbrain to the top of the spinal cord, including the locus coeruleus and raphe nuclei, as well as the basal forebrain and substantia nigra. Because of the existence of a diffuse projection from brain stem origins to the remote areas of the brain and spinal cord, Woolf (1996) introduced the term "global neurons." This system might be extended to motor neuron disease, which can, like Parkinson's disease, co-exist with Alzheimer-like features 
(Massman et al., 1996); motor neurons comprise part of the "global cell population." Indeed, the common pathological association for the Alzheimer's and Parkinson" disease is also demonstrated for the motor neurons (Bataille et al., 1998). Accordingly, Greenfield and Vaux (2002) proposed that these three major neurodegenerative disorders can be associated by a common mechanism.

\section{Restless Legs Syndrome (RLS) and Periodic Limb Movement Disorder (PLMD)}

RLS (nocturnal myoclonus) is a disorder characterized by disagreeable leg sensations, usually prior to sleep onset, causing an irresistable urge to move the legs. The cause is not known. It is often accompanied by "creapy-crawly" sensations in the lower legs that make the person uncomfortable unless the legs are moved. Patients with RLS exhibit major depression and those with PLMD exhibit generalized anxiety disorder (Saletu et al., 2002).

\section{Psychiatric Disorders}

In anxiety, the elevated frontal EMG activity is a common finding (see, e.g., Sainsbury and Gibson, 1954; Hazlett et al., 1994). Goldstein (1964) reported that the level effects (anxious vs. non-anxious) were significant for the right forearm extensors and right masseter. There were abrupt breaks in frontal EMG, as in trembling, in association with clinical anxiety (Malmo et al., 1951). Frindlund et al. (1986) investigated the motor irregularities in relation to anxiety. The authors found that the EMG level was higher in high than low-anxiety subjects, and concluded "the greater EMG levels in anxious subjects are due to a greater number of bursts of EMG activity associated with agitated movement."

Malmo and Malmo (2000) reported changes in EMG during hallucinations, which are prominent among the core symptoms of schizophrenia. Inouye and Shimizu (1970) recorded EMGs from the speech muscles during verbal hallucinations in nine schizophrenic patients. There were increased EMG levels in most patients during verbal hallucinations. Cerny (1965) reported increased EMG levels in 9 of 28 psychotics during hallucinations. McGuigan (1966) studied EMG immediately preceeded hallucinations. His patient pressed a button upon hearing voices, and consistently showed increased amplitude of the chin EMG immediately before auditory hallucinations. During the same period, that is, prior to hearing voices, there was whispering that could be heard on the tape. This a common finding reported by others, that is, tongue and lip movements prior to hearing voices (but not during hallucinations). Thus, the verbal hallucinations may be processed by neural mechanisms for 
language, but the muscle contractions generating speech appear to be gated out (Gandevia, 1994). According to Liberman et al. (1967), verbal hallucinations depend on supraspinal neural structures that control movements. There is indeed evidence that the central motor-speech mechanisms may be responsible for verbal hallucinations. Accordingly, Bick and Kinsbourne (1987) showed that verbal hallucinations in schizophrenic patients ceased during opening the mouth wide, although other actions not involving speech muscles (e.g., a fist and holding it tight) did not.

There are more evidence indicating that hallucinations are motoric in origin rather than being sensory. Silbersweig et al. (1995) could not find enhanced regional cerebral blood flow in the primary visual and auditory cortices during auditory verbal hallucinations, but there were also enhanced blood flow in the motor regions of the brain. So, the neural mechanisms for hallucinations closely involve the motor system, but these may not be revealed by EMG because the muscular contractions during speech appear to be gated out during hallucinations.

The prevalence of involuntary movements in schizophrenia approaches $100 \%$ (Quinn et al., 2001), but these patients received prolonged exposure to antipsychotic medication. However, in numerous studies concerning schizophrenia, spontaneous movement abnormalities were reported to occur both in medicated and neuroleptic-free patients (see for a review, Walker, 1994). Cassidy et al. (1998) reported more spontaneous dyskinetic-like movements in individuals with schizotypal personality than subjects with schizoid personality or healthy controls. Recently, Walker et al. (cited in Neumann \& Walker, 1999) reported an elevated rate of spontaneous involuntary movements in schizotypal personality disorder, which is seen in some relatives of schizophrenia patients with similar symptoms of schizophrenia. Moreover, Caliguiri and Lohr (1994) reported more manual force instability in neuroleptic-free schizophrenia patients with positive symptom ratings than comparison subjects. Vrtunski et al. (1986) studied response time and fine motor control during a classification task in schizophrenics and nonschizophrenics; the latter responded more quickly and exhibited a smoother and faster motor response on all tasks, compared to schizophrenics. The authors suggested: "the decisions about the abstract referential meaning of words and pictures produce greater cognitive loads in schizophrenics than in nonschizophrenics." (Vrtunski et al., p. 275, 1989) also investigated several aspects of fine motor control in schizophrenics, and found that the motor steadiness prior to the button-press was reduced; the motor response was made with excessive force (hyperdynamia), and agonist-antagonist synchrony was impaired (more contralateral motor overflow 
consequent of increased force in the non-responding hand), suggesting an involuntary movement.

Neumann and Walker (1999) concluded on page 159 that

These and related findings suggest that the brain regions that give rise to schizophrenia and spectrum disorders may also play a role in motor regulation. Further, because motor dysfunction is known to precede the clinical onset of schizophrenia by many years (Walker et al., 1994), motor assessments may be promising, along with other indicators (Neumann \& Walker, 1996), for identifying individuals at risk.

There are indices for the various syndromes of motor dysfunction. For instance, patients with Parkinson's disease show a pronounced increase in movement time, but not in reaction time or involuntary movement (Ebmeir et al., 1992), whereas schizophrenia patients manifest increased reaction time and involuntary movement, but not movement time (Caliguri et al., 1993). Neumann and Walker (1999) studied the changes in an instrumental motor task administered to the adult subjects with schizotypal personality disorder, and found that these subjects manifested a motor performance profile similar to that shown by schizophrenia patients. The findings appeared to be specific for schizotypic personality disorder, especially for the right-hand responses, indicating problems in left-brain functioning, which is frequently reported to be dysfunctional in schizophrenia (see Miller et al., 1995), as it is for the schizotypal subjects (Mikhailova et al., 1996; Sailsbury et al., 1996). Interestingly enough, the heightened dopamine-receptor activation was reported to induce both movement abnormalities and schizophrenia-spectrum symptoms (see Walker, 1994).

There are many reports indicating a coupling of schizophrenia with the motor system. For instance, there is also a dysfunction of smooth pursuit eye movements accompanying this illness. The dysfunction in smooth pursuit eye movements is one of the co-familial traits, which have higher recurrence rates than schizophrenia itself. This psychomotor event, appearing only if the subject tracks a moving target, occurs in about 40 to $80 \%$ of schizophrenic patients and about 25 to $40 \%$ of their first degree relatives (Holzman, 2000). Thus, many studies showed a high prevalence of discrete motor disturbances in schizophrenic patients. In this context, Tigges et al. (2000) studied the neurological soft signs, which are discrete motor and sensory disorders that cannot be linked to special cerebral lesions or dysfunction (Tigges et al., 2000), in schizophrenic patients. This event was observed 
as early as in 1919 by Kraepelin. This is seen more often in schizophrenic patients than in other psychiatric patients or healthy controls, independent from neuroleptic medication (Schroeder et al., 1992; Gupta et al., 1995). Moreover, the neurological soft signs are related to disorders of motor coordination and negative symptoms in schizophrenia (Heinrichs \& Buchanan, 1988; Manschreck et al., 1990). Tigges et al. (2000) found that the regularity of repetitive hand movements was considerably impaired in schizophrenics compared to the healthy controls, especially on the left side, indicating a right-hemisphere dysfunction. Their results were consistent with the findings of Walker et al. (1994), who found a predominance of motor abnormalities on the left side of the body in schizophrenics. These results indicated that a right-hemispheric brain damage, contrary to a left-hemisphere hypothesis (see Crow, 1990).

Another psychomotor disturbance, the obsessive compulsive disorder was found to be frequently occurred in schizophrenics (23.5\%), as reported by Poyurovsky et al. (2001), who defined obsessions as intrusive, unwanted, and repeated thoughts and compulsions as the performance of repetitive goal-directed rituals clinically indistinguishable from schizophrenic mannerism or posturing. Porto et al. (1997) had found a much higher proportion $(46 \%)$.

"The meaning and relevance of the increased rates of neuromotoric deviation observed in patients with schizophrenia and their biological relatives remain unclear. ... Among high-risk offspring, an increased rate of neuromotoric deviation is very clearly associated with increased rates of current mental disorder..." (McNeil et al., p. 281, 2003).

Deviations in the motor system $(N D)$ were found among patients with schizophrenia, as compared both with normal controls and with psychiatric patients with other disorders (Woods et al., 1986; Heinrichs \& Buchanan, 1988; Cantor-Graae et al., 1994; Ismail et al., 1998). Interestingly, there is a significant association between increased ND in schizophrenics and their global severity of illness (Ismail et al., 1998); this condition was also found in the mentally healthy first degree biological relatives of schizophrenics (Ismail et al., 1998; Kinney et al., 1986; Rossi et al., 1990; Cantor-Graae et al., 1994; Egan et al., 2001).

Is the neuromotor deviation a general characteristic within families with schizophrenia? In other words, would it be an index for the personal risk for mental illness, versus an individual's personal liability for mental illness. Some studies agree with this view: ND would be a sign for personal liability. Namely, an increased ND was observed during childhood in preschizophrenics (Walker 
\& Lewine, 1990; Walker et al., 1994). Chronicity among schizophrenics was better predicted by ND than any other premorbid characteristics (Ricks \& Berry, 1970, cited by McNeil et al., 2003). On the other hand, the development of schizophrenia, schizophrenia-spectrum disorders or schizotypal personality could be predicted using ND (see Hans et al., 1999). Neuromotoric items representing "overflow" (e.g., choreatic movements, tremor) were correlated with mental characteristics, such as language disorders and enuresis; an increase in ND was associated with an increase in rates of mental disorders (McNeil et al., 2003).

\section{Depression}

This is also a psychomotor disturbance. When depression occurs, movement generally lessens (slowing), or changes to a nonproductive agitation. In general, the psychomotor slowing is the main characteristic of depression. The clinical depression as also known as "depressive disorder" or "major depression" is characterized by loss of pleasure in almost all activities, loss of reactivity, depressed mood, weight loss, and marked psychomotor slowing or agitation among others (see Doris et al., 1999).

There are pharmacological interventions to treat depression, but there is not an adequate pharmacological therapy; antidepressants are often not beneficial; the patients often stop taking antidepressants generally within three weeks. The exercise therapy is used for several decades, and the literature on this subject is steadily growing. In general, the aerobic exercise was found to be beneficial in the treatment of depression (see, e.g., Moore \& Blumenthal, 1998; Dimeo et al., 2001; Dunn et al., 2001; Brosse et al., 2002; Neidig et al., 2003). However, Ernst et al. (1998) performed systematic literature searches about complementary therapies in the treatment of depression, and concluded that scientific data to support the efficacy of complementary therapies is extremely limited. Furthermore, Lawlor and Hopket (p. 763, 2001) stated that "the effectiveness of exercise in reducing symptoms of depression cannot be determined..."

Haase and Tan (1965) studied the effects of amphetamine on the spinal motor system in cats. Stimulant drugs such as amphetamines were used in the therapy of depression, and to improve memory, attention, and thinking. Interestingly, Haase and Tan (1965) found that amphetamine increased the alphaand gamma-motoneuronal activity in decerebrate and/or spinalized cats; the duration and frequency of the tonic alpha motoneurons increased considerably, but only in extensor system. This increase in extensor motoneuronal activity was accompanied by a decrease in flexor-motoneuronal activity. Furthermore, Tan 
and Henatsch (1969) studied the effects of the antidepressive agent imipramine upon the spinal motor system of decerebrate cats. The authors reported that, following imipramin injection, the discharge frequency of the extensor alpha motoneurones increased; the tonically discharging flexor motoneurones ceased firing; there was a regular and strong reduction in the spinal recurrent inhibition and presynaptic inhibition; because the affected systems are normally inhibiting the extensor motoneuronal system more strongly than the flexor motoneuronal system, the net result was a predominant increase in the extensor motor system. The authors suggested that "the enhanced motor activity favoring the postural extensor motricity might be an important basis for the antidepressive actions of imipramine and related substances." (p. 337)

The two latter studies suggest that the psychomotor slowing in depression can be successfully treated if the extensor-system activity is increased, without using the pharmacological agents. Exercise increasing the tonic extensorsystem activity may be a beneficial method for the treatment of depression, without using any medicine. As mentioned earlier, there are inconsistencies in the scientific literature concerning the effects of exercise on depression. They did not, however, study the extensor and flexor systems separately. The experiments reviewed herein suggest that exercises especially increasing the extensor-system activity may be beneficial for the treatment of depression.

\section{PSYCHOMOTOR THEORY OF HUMAN MIND}

This article has presented some of the basic theories concerning the mind/body or the mind/brain relations and scientifically established facts about the psychomotor interactions. First of all, the aforementioned studies indicated that in psychomotor domain, not the mind-brain duality or unity, but the mind-brain-body triad as a functional unit is essential in health and disease, because the mental events (mind) do not end in the brain; they further control the movements (body).

The studies suggest that (i) psychic system is closely coupled with motor system; (ii) mental and motor events share the same neural substrate, the motoneuronal system; (iii) brain is the liaison between mind and body.

According to the aforementioned results the motor and mental systems share the same motoneuronal domain within the central nervous system. This is the psychomotor system, being the quintessence of the "psychomotor theory," which argues that the human mind may be an emergent property of the fluctuating activities within the central motor nucleus, expressed by human language. The presented scientific literature suggests that the mental 
events (mind) are always coupled with cortico-spinal motor system through the feedback mechanisms between mind and brain. This is, however, not a dualistic view. It is rather a monistic theory, suggesting that all psychic events may in fact be the expressions of the fluctuating motor activities within the brain. Thus, the psychomotor theory emphasizes the leading role of the motor system in the emergence of the mental events, which would not be more than an expression of the motoric using human language. In this context, Sherrington, despite his dualistic philosophy, accentuated the role of the motor system in relation to mind, stating that "mind is attached to a voluntary motor act performed with skill ... mind seems to have arisen in connection with the motor act ... where motor integration progressed and where motor behavior progressively evolved, mind progressively evolved."

Consistent with the close coupling between the human mind and the human motor system, the parallel evolution of the frontal lobe regions and hands in hominids suggests motor activity as the basis of human intelligence (Seitz, 2000).

According to the psychomotor theory, the human mind may be an emergent property of the motor system, expressed by human language. As also mentioned earlier, Sir John Eccles, a contemporary neurophysiologist, a Nobel Prize winner, and a prominent defendant of the dualist-interactionist theory, could not explain the human mind without considering the left brain, that is, the liaison brain, which is the dominant hemisphere whit language capacities. As mentioned earlier, he summarized his views: “. . .the self-conscious mind as an independent entity that actively engages in the reading out from a multitude of active centers in the modules of the liaison areas of the dominant cerebral hemisphere," which is mainly engaged in language. Thus, the psychomotor theory emphasizes the prominent role of language in the emergence of mind. Accordingly, it can be stated that there would be no human mind if there were no human language. It can also be stated that the human motor system, human language, and human mind may be co-evolved in the history of human beings.

In brief, the mental events may emerge as an active mind from the central motoneuronal system, the output of which can induce movements in the body, and the output of the muscular activity feed-back to the central motoneuronal system, emerging the mind at the same time. The motor system is the nucleus, which coupled with mind quite tightly, so that any disturbance in this nucleus reflects as a mental disorder in the previously healthy persons. This article presented examples about the mind-brain-body relations in health and disease. Because of the close relation between mental and motor events, the 
motoneuronal diseases are usually seen with mental disturbances. According to the new theory of human mind, the existence of any purely mental disorder is unconceivable because the mental events emerge only from the motoneuronal system; there is no independent mind. Therefore, mental disturbances may only originate from motoneuronal disorders; there may be no psychiatric illness without an accompanying motoneuronal disorder.

The concepts about the neurological and psychiatric diseases are slowly changing. Interestingly enough, Parkinson's disease, Alzheimer's disease, and motor neuron disease all share the same motoneuronal systems including the socalled global neurons (see Greenfield \& Vaux, 2002). Normalizing these global neurons may be enough to treat all the neurological and psychiatric symptoms of the motor neuron diseases. Accordingly, the psychomotor theory may open new strategies for the therapy of psychiatric disorders. For instance, it may be quite possible to treat depression, only increasing the extensor motoneuronal activity, as mentioned earlier. The motor system may be the key factor in understanding and improving behavior in health and disease.

The global output of the cortico-spinal motor system may be the key element determining the psychological well-being. In this context, McNeil et al. (p. 219, 2003) have stated that “... an increased rate of neuromotoric deviation is very clearly associated with increased rates of current mental disorder." With regard to psychomotor coupling, Walker (p. 453, 1994) reported that "The heightened dopamine-receptor activation induces both movement abnormalities and schizophrenia-spectrum symptoms." "These and related findings suggest that the brain regions that give rise to schizophrenia and spectrum disorders may also play a role in motor regulation at the same time. Further, because motor dysfunction is known to precede the clinical onset of schizophrenia by many years (Walker et al., 1994), motor assessments may be promising, along with other indicators (Neumann and Walker, p. 159, 1996), for identifying individuals at risk."

Sperry (1952) also accentuated the prominent role of the motor system in cognitive activities, nearly half a century ago:

The principal function of the nervous system is the coordinated innervations of the musculature. Its fundamental anatomical plan and working principles are understandable only on these terms ... even the highest human cognitive activities, even those requiring no motor output, there are inevitably to be found certain critically essential motoric neural events. (p. 298) 
Gold and Stoljar (p. 869, 1999) argued "The idea is not of course that neuroscience will explain everything about the mind; perhaps there are aspects of the mind we will never explain." In contrast to this statement, the psychomotor theory seems to be of utmost importance for understanding and improving the human mind in health and disease in the near future.

\section{REFERENCES}

Abrahams, S., Goldstein, L. H., Al-Chalabi, A., Pickering, A., Morris, R. G., Passingham, R. E., Brooks, D. J., \& Leigh, P. N. (1997). Relation between cognitive dysfunction and Pseudobulbar palsy in amyotrophic lateral sclerosis. Journal of Neurology, Neurosurgery, and Psychiatry, 62, 464-472.

Andreasen, N. C., Paradiso, S., \& O`Leary, D. S. (1998). "Cognitive dysmetria” as an integrative theory of schizophrenia: A dysfunction in cortical-subcorticalcerebellar Circuitry. Schizophneia Bulletin, 24, 203-218.

Akshoomoff, N. A., \& Courchesne, E. (1994). ERP evidence for a shifting attention deficit in patients with damage to the cerebellum. Journal of Cognitive Neuroscience, 6, 388-399.

Allain, H., Schuck, S., \& Mauduit, N. (2000). Depression in Parkinson's disease. BMJ, 320, 1287-1288.

Bak, T. H., \& Hodges, J. R. (2001). Motor neuron disease, dementia and aphasia: Coincidence, co-occurrence or continuum? Journal of Neurology, 248, 260-270.

Barson, F. P., Kinsella, G. J., Ong, B., \& Mathers, S. E. (2000). A neuropsychological investigation of dementia in motor neuron disease (MND). Journal of the Neurological Sciences, 180, 107-113.

Bartlett, F. C. (1958). Thinking: An experimental and social study. New York: Basic Books.

Bataille, S., Portalier, P., Coulon, P., \& Ternaux, J. P. (1998). Influence of acetylcholinesterase on embryonic spinal rat motoneurones growth in culture: A quantitative morphometric study. European Journal of Neuroscience, 10, 560572.

Baum, E. (1995). Multiple personality disorder: A group movement therapy approach. In F. Levy (Ed.), Dance and other expressive art therapies: When words are not enough. (pp. 83-92). New York: Routledge.

Berger, B. G. (1984). Running away from anxiety and depression: A female as well as male race. In M. L. Sachs \& G. Buffone (Eds.), Running as therapy: An integrated approach. Lincoln: University of Nebraska Press.

Bick, P. A., \& Kinsbourne, M. (1987). Auditory hallucinations and subvocal speech in schizophrenic patients. American Journal of Psychiatry, 144, 222-225.

Blackburn, J. (2003). Trager psychophysical integration-an overview. Journal of Bodywork and Movement Therapies, 7, 233-239. 
Brosse, A. L., Sheets, E. S., Lett, H. S., \& Blumenthal, J. A. (2002). Exercise and the treatment of clinical depression in adults: recent findings and future directions. Sports Medicine, 32, 741-760.

Cabanis, P. J. G. (1805). On the relation between the physical and moral aspects of man. Baltimore: The Johns Hopkins University Press.

Caligiuri, M., Lohr, J. B., Panton, D., \& Harris, J. M. (1993). Extrapyramidal motor abnormalities associated with late-life psychosis. Schizophrenia. Bulletin, 19, 747754.

Caliguiri, M. P., \& Lohr, J. B. (1994). A disturbance in the control of muscle force in neuroleptic-naïve schizophrenic patients. Biological Psychiatry, 35, 104-111.

Cantor-Graae, E., McNeil, T. F., Rickler, K. C., Sjostrom, K., Rawlings, R., Higgins, E. S., \& Hyde, T. M. (1994). Are neurological abnormalities in well discordant monozygotic co-twins of schizophrenic subjects the result of perinatal trauma American Journl of Psychiatry, 151, 1194-1199.

Carpenter, W. B. (1874). Principles of mental physiology, with their applications to the training and discipline of the mind, and the study of its morbid conditions (p. 737). London: Henry S. King \& Co.

Cassidy, S. L., Adami, H., Moran, M., Kunkel, R., \& Thaker, G. V. (1998). Spontaneous Dyskinesia in subjects with schizophrenia spectrum personality. American Journal of Psychiatry, 155, 70-75.

Cerny, M. (1965). On neurophysiological mechanisms in verbal hallucinations: An electrophysiological study. Activitas Nervosa Superior (Prague), 7, 197-198.

Cohen, S. O., \& Walco, G. A. (1999). Dance/movement therapy for children and adolescents with cancer. Cancer Practice, 7, 34-42.

Cooper, P. N., Jackson, M., Lennox, G., Lowe, J., \& Mann, D. M. (1995). Tau, ubiquitin, and Alpha B-crystalin immunohistochemistry define the principal causes of degenerative Frontotemporal dementia. Archive of Neurology, 52, 1011-1015.

Crow, T. J. (1990). Temporal lobe asymmetries as the key to the etiology of schizophrenia. Schizophrenia Bulletin, 16, 433-443.

Davis, R. C. (1937). The relation of certain muscle action potentials to "mental work." Science series No. 5. Indiana University Publications, Indiana, pp. 5-29.

Dayi, E., Gungormus, M., Okuyan, M., \& Tan, Ü. (2002). Predictability of hand skill and cognitive abilities from craniofacial width in right- and left-handed men and women: Relation of skeletal structure to cerebral function. International Journal of Neuroscience, 112, 383-412.

DeLong, M. R. (1990). Primate models of movement disorders of basal ganglia origin. Trends in the Neurosciences, 13, 281-185.

Dimeo, F., Bauer, M., Varahram, I., Proest, G., \& Halter, U. (2001). Benefits from aerobic exercise in patients with major depression: A pilot study. British Journal of Sports Medicine, 35, 114-117.

Doris, A., Ebmeier, K., \& Shajahan, P. (1999). Depressive illness. Lancet, 354, 13691375. 
Dunn, A. L., Trivedi, M. H., \& O`Neal, H. A. (2001). Physical activity dose-response effects on outcomes of depression and anxiety. Medical Science for Sports and Exercise, 33, 587-597.

Ebmeir, K. P., Potter, D. D., \& Cochrane, R. H. (1992). Event-related potentials, reaction time and cognitive performance in idiopathic Parkinson's disease. Biological Psychology, 33, 73-89.

Eccles, J. (1975). Facing reality: philosophical adventures of a brain scientist (p. 174). New York: Springer Verlag.

Eccles, J. C. (1977). My scientific odyssey. Annual Review of Physiology, 39, 1-8.

Eccles, J. C., \& Popper, K. R. (1977). The self and its brain. An argument for interactionism (p. 355). Berlin, New York: Springer International.

Eckstein, D., \& Keeling, G. (1991). Principles of health from eastern disciplines are finding their way into Western workouts: East meets West. IDEA Today, 10, 47-50.

Egan, M. F., Hyde, T. M., Bonomo, J. H., Mattay, V. S., Bigelow, L. H., Goldberg, T. E., \& Weinberger, D. R. (2001). Relative risk in neurological signs in siblings of patients with schizophrenia. American Journal of Psychiatry, 158, 1827-1834.

Ernst, E., Rand, J. I., \& Stevinson, C. (1998). Complementary therapies for depression: An overview. Archive of General Psychiatry, 55, 1026-1032.

Evans, J. B. (2003). In two minds: Dual-process accounts of reasoning. Trends in Cognitive Sciences, 7, 454-459.

Fischer, K. W., \& Bidell, T. R. (1998). Dynamic development of psychological structures in action and thought. In W. Damon (Ed.), Handbook of child psychology: Vol.1: Theoretical models of human development. (pp. 467-561). New York: Wiley.

Flourens, M-. J-. P. (1824). Investigations of the properties and functions of the various parts which compose the cerebral mass (pp. 85-122). Springfield, Illinois: Charles C. Thomas Publisher.

Gandevia, S. C. (1994). Peripheral and central correlates of attempted voluntary movements (pp. 208-209). Commentary on Jeannerod, M. The representing brain: Neural correlates of motor intention and imagery. Behavioral and Brain Sciences, 17, 187-245.

Gardner, H. (1993). Frames of mind: The theory of multiple intelligences. New York: Basic Books.

Gold, I., \& Stoljar, D. (1999). A neuron doctrine in the philosophy of neuroscience. Behavioral and Brain Science, 22, 809-869.

Goldstein, I. B. (1964). Physiological responses in anxious women patients. Archives of General Psychiatry, 10, 382-388.

Greenfield, S., \& Vaux, D. J. (2002). Parkinson's disease, Alzheimer's disease and motor neurone disease: Identifying a common mechanism. Neuroscience, 113, 485-492.

Gupta, S., Adreasen, N. C., Arndt, S., Flaum, M., Schultz, S. K., Hubbard, W. C., \& Smith, M. (1995). Neurological soft signs in neuroleptic-naïve and neuroleptic treated schizophrenic patients and in normal comparison subjects. American Journal of Psychiatry, 152, 191-196. 
Haase, J., \& Tan, Ü. (1965). Die excitatorischen Wirkungen von Desoxyephedrine (Pervitin) Auf die tonische spinalmotorik der Katze. Naunyn-Schmiedeberg's Arch. Exp. Path. Pharmak., 252, 20-31.

Hans, S. L., Nuechterlein, K. H., Asarnow, R. F., Styr, B., \& Auerbach, J. G. (1999). Neurobehavioral deficits at adolescence in children at risk for schizophrenia: The Jerusalem infant development study. Archive of General Psychiatry, 56, 741748.

Heinrichs, D. W., \& Buchanan, R. W. (1988). Significance and meaning of neurological signs in schizophrenia. American Journal of Psychiatry, 145, 11-18.

Hazlett, R. L., McLeod, D. R., \& Hoehn-Saric, R. (1994). Muscle tension in generalized anxiety disorder: Elevated muscle tonus or agitated movement? Psychophysiology, 31, 189-195.

Hebb, D. O. (1980). Essay on mind. Hillsdale, NJ: Lawrence Erlbaum.

Hinshaw, K. E. (1992). The effects of mental practice on motor skills performance: Critical evaluation and meta-analysis. Imagination, Cognition, and Personality, $11,3-25$.

Holton, J. L., Revesz, T., Crooks, R., \& Scaravilli, F. (2002). Evidence for pathological involvement of the spinal cord in motor neuron disease-inclusion dementia. Acta Neuropathologia, 103, 221-227.

Holzman, P. S. (2000). Eye movements and the search for the essence of schizophrenia. Brain Research Reviews, 31, 350-356.

Inouye, T., \& Shimizu, A. (1970). The electromyographic study of verbal hallucination. Journal of Nervous and Mental Diseases, 151, 415-422.

Ismail, B., Cantor-Graae, E., \& McNeil, T. F. (1998). Neurological abnormalities in Schizophrenic patients and their siblings. American Journal of Psychiatry, 155, 84-89.

Ito, M. (1993). Movement and thought: Identical control mechanisms by the cerebellum. Trends in the Neurosciences, 16, 448-450.

Ito, T., Hokezu, Y., Mori, T., Watanabe, O., \& Nagamatsu, K. (2001). A case of motor Neuron disease with presenil dementia showing bilateral degeneration of the pyramidal Tract on cranial MRI. Rinsho Shinkeigaku, 41, 60-63.

Jackson, J. H. (1873). Clinical and physiological researches on the nervous system (reprints) No. 1-On the localization of movements in the brain (p. 21). Lancet.

Kant, I. (1871). (Translated by J. M. D. Meiklejohn). Critiques of pure reason (p. 69). EBooks \& Adelaide, 2004.

Kern, D., \& Baker, J. (1997). A comparison of a mind/body approach versus a conventional approach to aerobic dance. Women's Health Issue, 7, 30-37.

Kinney, D. K., Woods, B. T., \& Yurgelun-Todd, D. (1986). Neurologic abnormalities in Schizophrenic patients and their families: II. Neurologic and psychiatric findings in relatives. Archive of General Psychiatry, 43, 665-668.

Kraepelin, E. (1919). Dementia praecox and paraphenia. Edinburgh: Livingstone.

Laban, R. (1975). Modern educational dance. 3rd edn. Boston: Plays, Inc. 
Laban, R., \& Lawrence, F. C. (1974). Effort: Economy of human movement. 2nd edn. Boston: Plays, Inc.

Lawlor, D. A., \& Hopker, S. W. (2001). The effectiveness of exercise as an intervention in the management of depression: systematic review and meta-regression analysis of randomized trials. British Medical Journal, 322, 763-767.

Leiner, H. C., Leiner, A. L., \& Dow, R. S. (1986). Does the cerebellum contribute to mental skill? Behavioral Neuroscience, 100, 443-454.

Leiner, H. C., Leiner, A. L., \& Dow, R. S. (1989). Reappraising the cerebellum: What does the hind brain contribute to the forebrain? Behavioral Neuroscience, 103, 998-1008.

Leste, A., \& Rust, J. (1990). Effects of dance on anxiety. American Journal of Dance Therapy, 12, 19-26.

Liberman, A. M., Cooper, F. S., Shankweiler, D. P., \& Studdert-Kennedy, M. (1967). Perception of the speech code. Psychological Review, 74, 431-461.

MacDonald, J. (1992). Dance? In H. Payne (Ed.), Dance movement therapy: Theory and practice. (pp. 202-217). London: Routledge.

Malmo, R. B., \& Malmo, H. P. (2000). On electromyographic (EMG) gradients and movement-related brain activity: significance for motor control, cognitive functions, and certain psychopathologies. International Journal of Psychophysiology, 38, 143-207.

Malmo, R. B., Shagass, C., \& Davis, J. F. (1951). Electromyographic studies of muscle Tension in psychiatric patients under stress. J. Clinical and Experimental Psychopathology, 12, 45-66.

Manschreck, T. C., Keuthen, N. J., Schneyer, M. L., Celada, M. T., Laughery, J., \& Collins, P. (1990). Abnormal involuntary movements and chronic schizophrenic disorders. Biological Psychiatry, 27, 150-158.

Massman, P. J., Kreiter, K. T., Jankovic, J., \& Doody, R. S. (1996). Neuropsychological functioning in cortico-basal ganglionic degeneration: Differentiation from Alzheimer's disease. Neurology, 46, 720-726.

McDonald, W. M., Richard, I. H., \& DeLong, M. R. (2003). Prevalence, etiology, and treatment of depression in Parkinson's diseas. Biological Psychiatry, 54, 363-375.

McGuigan, F. J. (1966). Covert oral behavior and auditory hallucinations. Psychophysiology, 3, 73-80.

McNeil, T. F., Cantor-Graae, E., \& Blennov, G. (2003). Mental correlates of neuromotoric deviation in 6-year-olds at heightened risk for schizophrenia. Schizophrenia Research, 60, 219-228.

Middleton, F. A., \& Strick, P. L. (1994). Anatomical evidence for cerebellar and basal ganglia involvement in higher cognitive function. Science, 266, 458-461.

Mikhailova, E. S., Viadimirova, T. V., Iznak, A. F., Tsusulkovskaya, E. J., \& Sushko, N. V. (1996). Abnormal recognition of facial expression of emotions in depressed patients with major depression disorder and schizotypal personality disorder. Biological Psychiatry, 40, 697-705. 
Miller, E. N., Fujioka, T. A., Chapman, L., \& Chapman, J. (1995). Hemispheric asymmetries of function in patients with major affective disorders. Journal of Psychiatric Research, 29, 173-183.

Moore, K. A., \& Blumenthal, J. A. (1998). Exercise training as an alternative treatment for depression among older adults. Alternative Therapy and Health Medicine, 4, $48-56$.

Moretti, R., Torre, P., Antonello, R. M., De Masi, R., \& Cazzato, G. (2001). Complex cognitive disruption in frontal dementia related to motor neuron disease. Perceptual and Motor Skills, 92, 1213-1229.

Murray-Lane, M. B. (1995). Walls of addiction. In F. Levy (Ed.), Dance and other expressive art therapies: When words are not enough. (pp. 93-100). New York: Routledge.

Neidig, J. L., Smith, B. A., \& Brashers, D. E. (2003). Aerobic exercise training for depressive symptom management in adults living with HIV infection. Journal of the Association of Nurses in AIDS Care, 14, 30-40.

Neumann, C. S., \& Walker, E. F. (1999). Motor dysfunction in schizotypal personality disorder. Schizophrenia Research, 38, 159-168.

Ogles, B. M., Lynn, S. J., Masters, K. S., Hoefel, T. D., \& Marsden, K. (1994). Runner's cognitive strategies and motivations: Absorption, fantasy style, and dissociative experiences. Imagination, Cognition, and Personality, 13, 163-174.

Paillard, J. (1955). Reflexes et regulations d'origine proprioceptive chez l'homme. (pp. 293). Paris: Libraire Arnette.

Penfield, W. (1975). The mystery of the mind (p. xiii). Princeton, NJ: University Press. Popper, K. (1935). Logik der forschung (p. 31). Vienna: Julius Springer Verlag.

Popper, K., \& Eccles, J. C. (1977). The self and its brain, p. 283. Berlin, New York: Springer Verlag International.

Portet, F., Cadilhac, C., Touchon, J., \& Camu, W. (2001). Cognitive impairment in motor neuron disease with bulbar onset. Amyotrophic Lateral Sclerosis and Other Motor Neuron Disorders, 2, 23-29.

Porto, L., Bermanzohn, P. C., Pollack, S., Morissey, R., \& Siris, S. G. (1997). A profile of obsessive-compulsive symptoms in schizophrenia. CNS Spectrums, 2, 21-25.

Poyurovsky, M., Hramenkov, S., Isakov, V., Rauchverger, B., Modai, I., Schneidman, M., Fuchs, C., \& Weizman, A. (2001). Obsessive-compulsive disorder in hospitalized patients with chronic schizophrenia. Psychiatry Research, 102, 49-57.

Quinn, J., Meagher, D., Murphy, P., Kinsella, A., Mullaney, J., \& Waddington, J. L. (2001). Vulnerability to involuntary movements over a life time trajectory of schizophrenia approaches $100 \%$, in association with excessive (frontal) dysfunction. Schizophrenia Research, 49, 79-87.

Ranoux, D. (2000). Depression et maladie de Parkinson. Encephale, 26, 22-26.

Rossi, A., Cataldo, S., Di Michele, V., Manna, V., Ceccoli, S., Stratta, A., \& Casachia, M. (1990). Neurological soft signs in schizophrenia. British Journal of Psychiatry, $157,735-739$. 
Rose, S. (1995). Movement as metaphor: Treating chemical addiction. In F. Levy (Ed.), Dance and other expressive art therapies: When words are not enough. (pp. 101-108). New York: Routledge.

Sailsbury, D. F., Voglmaier, M. M., Seidman, L. J., \& MacCarley, R. W. (1996). Topographical abnormalities of P3 in schizotypal personality disorder. Biological Psychiatry, 40, 165-172.

Sainbury, P., \& Gibson, J. G. (1954). Symptoms of anxiety and tension and the accompanying physiological changes in the muscular system. Journal of Neurology, Neurosurgery, and Psychiatry, 17, 216-224.

Saletu, B., Anderer, P., Saletu, M., Hauer, C., Lindeck-Pozza, L., \& Saletu-Zyhlarz, G. (2002). EEG mapping, psychometric, and polysomnographic studies in restless leg syndrome (RLS) and periodic limb movement disorder (PLMD) patients as compared with normal subjects. Sleep Medicine, 3, S35-S42.

Schmidt, M. L., Zhukareva, V., Perl, D. P., Sheridan, S. K., Schuck, T., Lee, V., \& Trojanowski, J. Q. (2001). Spinal cord neurofibrillary pathology in Alzheimer disease and Guam Parkinsonism-dementia complex. Journal of Neuropathology and Experimental Neurology, 60, 1075-1086.

Schroeder, J., Niethammer, R., Geider, F. J., Reitz, C., Binkert, M., Jauss, M., \& Sauer, H. (1992). Neurological soft signs in schizophrenia. Schizophrenia Research, 6, 25-30.

Sherrington, C. (1953). Man on his nature (p. 248). New York: Doubleday.

Sherrington, C. S. (1940). Man on his nature (p. 287). Cambridge, UK: Cambridge University Press.

Seitz, J. A. (2000). The bodily basis of thought. New Ideas in Psychology, 18, 23-40.

Silbersweig, D. A., Stern, E., Frith, C., Canill, C., Holmes, A., Grootoonk, S., Seaward, J., McKenna, P., Chua, S. E., \& Schnorr, L. (1995). A functional neuroanatomy of hallucinations in schizophrenia. Nature, 378, 176-179.

Spencer, H. (1855). The principles of psychology (p. 620). London: Longman, Brown, Green, and Longmans.

Sperry, R. W. (1952). Neurology and the mind-brain problem. Am. Sci., 40, 291-312.

Sperry, R. W. (1980). Mind-body interactions: mentalism, yes; dualism, no. Neuroscience, 5, pp. 265-270.

Sudo, S., Fukutani, Y., Matsubara, R., Sasaki, K., Shiozawa, M., Wada, Y., Naiki, H., \& Isaki, K. (2002). Motor neuron disease with dementia combined with degeneration of striatonigral and pallidoluysian system. Acta Neuropathologia, 103, 521525 .

Tan, Ü. (1989a). The Hoffmann reflex from the flexor pollicis longus of the thumb in left-handed subjects: Spinal motor asymmetry and supraspinal facilitation to Cattell's intelligence test. International Journal of Neuroscience, 48, 255-269.

Tan, Ü. (1989b). Right and left hand skill in left-handers: Distribution, learning, and relation to nonverbal intelligence. International Journal of Neuroscience, 44, 235 249. 
Tan, Ü. (1989c). Manual proficiency in Cattell's Intelligence Test in left-handed male and female subjects. International Journal of Neuroscience, 44, 17-26.

Tan, Ü. (1990). Relation of hand skill to spatial reasoning in male and female lefthanders with left- and right-hand writing. International Journal of Neuroscience, 53, 121-133.

Tan, Ü. (1991). The inverse relationship between nonverbal intelligence and the latency of the Hoffmann reflex from the right and left thenar muscles in right- and left-handed subjects. International Journal of Neuroscience, 57, 219238.

Tan, Ü. (1996). Correlations between nonverbal intelligence and peripheral nerve conduction velocity in right-handed subjects: Sex-related differences. International Journal of Psychophysiology, 22, 123-128.

Tan, Ü., \& Gurgen, F. (1986). Modulation of spinal motor asymmetry by neuroleptic medication of schizophrenia patients. International Journal of Neuroscience, 30 , $165-172$.

Tan, Ü., \& Henatsch, H. D. (1969). Wirkungen von imipramin auf die spinalmotorischen Extensor- und flexor-systeme der Katze. Naunyn-Schmiedebergs Archieve fuer. Pharmakologie und Experimental Pathologie, 262, 337-357.

Tan, Ü., Okuyan, M., Albayrak, T., \& Akgun, A. (2003). Sex difference in verbal and spatial ability reconsidered in relation to body size, lung volume, and sex hormones. Perceptual and Motor Skills, 96, 1347-1360.

Tigges, P., Mergl, R., Frodl, T., Meisenzahl, E. M., Gallinat, J., Schroter, A., Riedel, M., Muller, N., Moller, H. J., \& Hegerl, U. (2000). Digitized analysis of abnormal hand-motor performance in schizophrenic patients. Schizophrenia Research, 45, 133-143.

Trojanowski, J. Q., Ishihara, T., Higuchi, M., Yoshiyama, Y., Hong, M., Zhang, B., Forman, M. S., Zhukareva, V., \& Lee, V. M. (2002). Amyotrophic lateral sclerosis/ parkinsonism dementia complex: Transgenic mice provide insights into mechanisms underlying a common taupathy in an ethnic minority on Guam. Experimental Neurology, 176, 1-11.

Tyndall, J. (1871). Fragments of science for unscientific people: A series of detached Essays, lectures, and reviews (pp. 119-120). London: Longmans Green and Co.

Uttal, W. R. (2001). The new phrenology..: Bradford Books, MIT Press.

Vrtunski, P. B., Simpson, D. M., \& Meltzer, H. Y. (1989). Voluntary movement dysfunction in schizophrenics. Biological Psychiatry, 25, 529-539.

Walker, E. (1994). The developmentally moderated expression of the neuropathology underlying schizophrenia. Schizophrenia Bulletin, 20, 453-480.

Walker, E. F., \& Lewine, R. J. (1990). Prediction of adult-onset schizophrenia from childhood home-movies of the patients. American Journal of Psychiatry, 147, 1052-1056.

Walker, E. F., Savoie, T., \& Davis, D. (1994). Neuromotor precursors of schizophrenia. Schizophrenia Bulletin, 20, 441-455. 
Wallace, R. K., Orme-Johnson, D. W., Mills, P. J., \& Dillbeck, M. C. (1984). Academic achievement and the paired Hoffman reflex in students practicing meditation. International Journal of Neuroscience, 24, 261-266.

Westbrook, B. K., \& McKibben, H. (1989). Dance/movement therapy with groups of outpatients with Parkinson's disease. American Journal of Dance Therapy, 11, 27-38.

Willingham, D. B. (1998). A neuropsychological theory of motor skill learning. Psychological Review, 105, 558-584.

Wilson, E. O. (1998). The hand: How its use shapes the brain, language, and human culture. New York: Random House.

Wilson, C. M., Brace, G. M., Munoz, D. G., He, B. P., \& Strong, M. J. (2001). Cognitive impairment in sporadic ALS: A pathologic continuum underlying a multisystem disorder. Neurology, 28, 651-657.

Woods, B. T., Kinney, D. K., \& Yurgelun-Todd, D. (1986). Neurologic abnormalities in schizophrenic patients and their families: 1. Comparison of schizophrenic, bipolar, and substance abuse patients and normal controls. Archive of General Psychiatry, $43,657-663$.

Woolf, N. J. (1996). Global and serial neurons from a hierarchically arranged interface Proposed to underlie memory and cognition. Neuroscience, 74, 625-651. 